\title{
A STUDY OF ESCAPE TIME FROM AN UNDERGROUND STREET IN A MOUNTAINOUS CITY
}

\author{
YIN PAN $^{1}$, TIEJUN ZHOU ${ }^{1} \&$ QIN YAN ${ }^{2}$ \\ ${ }^{1}$ Faculty of Architecture and Urban Planning, Chongqing University, China. \\ ${ }^{2}$ Vocational College of Chongqing Architectural Engineering, China.
}

\begin{abstract}
Taking the underground street in Three Gorges Plaza in the Shapingba District, Chongqing, as an example, the present study focused on a densely populated underground street downtown in a mountainous city, in which the issue of emergency evacuation in case of fire was discussed. The total evacuation number could be worked out according to the 'method of trip generation rate'; the length of escape routes and the width of escape exits were counted, and the maximum capacity of people for each emergency exit was calculated according to the unit capacity. Based on the above data, the escape route was built by the iterative programming algorithm so as to check the safety of the current underground street in the mountainous city, in order that technical support can be provided for effective countermeasures. Thus, the emergency evacuation capability of a downtown underground street in a mountainous city can be enhanced.

Keywords: Civil air defense projects, escape routes, escape time, mountainous city, underground street.
\end{abstract}

\section{INTRODUCTION}

Safety has already become one of the most important issues in the development of the city in the present world. Along with the continuous expansion of cities in China and the excessive concentration of population downtown, city planners in mountainous areas have used land intensively due to the shortage of construction land; the underground street has increased dramatically in size and number.

More and more people can be accommodated in the underground street, and the subsequent security risk within is greater than ever before; there are potential disasters such as fire, flood and terrorism, and especially fire [1]. There has been plenty of research into the safety of the underground space in the case of fire: for instance, the escape identification system, the evacuation route under conditions of poor visibility, the impact of obstacles on the escape, etc. Marciano and Vitetta [2] analyzed the different risks under different patterns of behavior. Russo and Chila [3] proposed that the importance of Stated Preference surveys to analyze user behaviors under evacuation conditions should be highlighted. The latest research includes the smart evacuation and escape system, the UK's Building Exodus simulation model for evacuation, which simulates reality through software development and analog simulation. Investigation and simulation research into disaster prevention in underground spaces, including evacuation routes, has been conducted in Taiwan and mainland China. Zhang [4] from Taiwan analyzed the most suitable evacuation route in the city and discussed the safety of the evacuation route from the perspective of safety, effectiveness and risk. Chen [5] carried out research on human evacuation behavior in subway stations and probed into escape safety in the subway by means of the weight value. Liang [6] analyzed the selection of emergency evacuation exits in an underground street in virtual reality, and through a simulation experiment drew a series of conclusions about how people select their exit during the emergency escape period. 
As regards research in mainland China, Chen [7] proposed to prevent disasters in underground commercial streets through the design of anti-disaster squares. Zeng et al. [8] analyzed critical dangerous conditions of fire in the underground commercial street and the features of evacuation; they confirmed the calculation method for safe escape time. Comparing safe escape time in the underground commercial street through theoretical calculation and software simulation, Huang [9] proposed simulating the evacuation process, emergency exits and the congestion in the evacuation route by means of numerical simulation, and showed that escape time is affected by the width of the emergency exit. The innovation point of this paper lies in the fact that the test result might differ according to the different requirements for disaster evacuation in China and America. Therefore, the study proposed improvements for the underground street, adapted from civil air defense projects in mountainous cities in China. Based on the previously mentioned researches, the present study is conducted through the calculation method appropriate for evacuation and escape in the case of fire in a mountainous city.

Whether people can escape in a safe time is of vital importance to verify the safety of the underground street adapted from civil air defense projects in the case of fire inside the underground street. Successful escape is the key to ensuring the safety of the evacuees. Therefore, the escape time in a densely populated downtown underground street in a mountainous city cannot be neglected. Finally, the appropriate improvement measures for the underground street in the mountainous city are proposed based on the research conclusion.

\section{CONTENTS AND METHODS}

\subsection{Contents}

The escape time during a disaster in an underground street is the main object of this study, and it is subject to factors such as escape behavior, escape routes, the layout plan and depth of the underground street, and the number of evacuees. The fire safety criteria in China are that all people should be evacuated within $3 \mathrm{~min}$ in the case of a disaster. Otherwise, with the spread of the fire, a secondary disaster such as smoke or gas will produce a life-threatening risk for people $[10,11]$. It is necessary to calculate whether people can escape from the underground street so as to verify whether the escape time meets the criteria. The length and width of the escape routes and the depth of the underground street directly affect the escape time. Hence, the underground escape routes are divided into vertical routes and horizontal ones, according to the running speed. The total evacuation number is worked out according to the 'method of trip generation rate'. Then, the study assumes that the fire source is at a certain location on the street, and that people are evacuated towards the nearest or most familiar exit: First going along the horizontal route, then approaching the ground exit by the vertical route, and finally, successfully getting out (Fig. 1).

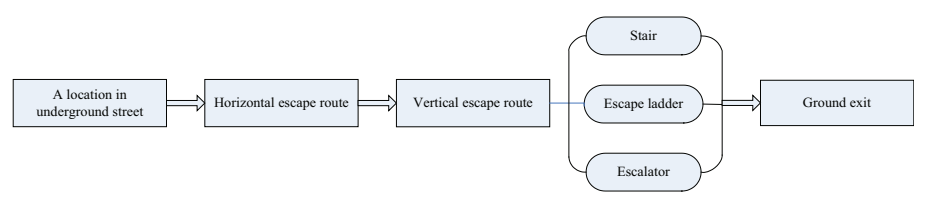

Figure 1: The constitution of the escape routes. 


\subsection{Methods}

There are currently 30 types of evacuation performance evaluation models at home and abroad, almost all of which assume that people will choose the shortest way to escape from the building space $[12,13]$. The iterative programming algorithm can resolve the multistage and resolvable decision problems, so that escape routes can be selected properly. For the iterative programming method, the best solution can be worked out based on the original status, the future status and the strategy derived from the decision. This method divides the original problem into several sub-problems, and the solution to the original problem can be worked out based on the solution to the sub-problems [14]. In general, the iterative programming method can be designed according to the following steps: (1) find the property of the optimal solution and describe its structural features, (2) define the optimal solution recursively, (3) work out the optimal solution in the bottom-up model, and (4) construct the optimal solution based on the information from the calculation of the optimal value.

\subsubsection{Formula 1}

According to the terms of the design criteria NFPA.130 2.5.3.2, the requirement for emergency evacuation in an underground street is that all the people should be evacuated to the ground exit within $6 \mathrm{~min}$. Chen [5] proposed that the escape time required for the last person to approach the ground exit equals the number of people to be evacuated from the underground street divided by the exit capability of the underground street.

\subsubsection{Formula 2}

To measure whether the escape time from the farthest point to the exit in the corresponding area meets the set time requirement, the escape formula in China and Japan Togawa [8] is as follows:

$$
\begin{gathered}
\text { Time required in vertical escape: } T_{1}=\frac{N_{a}}{B_{i} N_{i}}+\frac{L_{1}}{V_{1}} \\
\text { Time required in horizontal escape: } T_{2}=L_{2}+V_{2} \\
\text { Total time: } T=T_{1}+T_{2}
\end{gathered}
$$

In the formula, $N_{\alpha}$ is the total evacuation number; $N_{i}$ is the total number of people in the corresponding exit; $B_{i}$ is the width of the corresponding exit; $L_{i}$ is the vertical escape distance; $V_{l}$ is the vertical escape speed; $L_{2}$ is the horizontal escape distance; and $V_{2}$ is the horizontal escape speed.

\section{SURVEY AND DATA}

The mountainous city is characterized by remarkable changes in height difference; thus, the exit location is subject to the terrain. The greatest difference between an underground street in a city built in a mountainous region and one built on a plain lies in the fact that the former is deeper, and sometimes the exits are parallel with the street due to height difference. However, underground streets adapted from civil air defense projects are usually asymmetric so the escape routes in the underground street of a mountainous region are more complex than 
those in a city on a plain, which increases the difficulty and extends the time for emergency evacuation. Therefore, the underground street adapted from civil air defense projects in a mountainous city is chosen as the typical case. It is located in the Three Gorges Plaza in Shapingba District, Chongqing, with a population of 710,000, and it is in basement-1 of the Three Gorges Plaza, and expanded from the atrium of the underground plaza. In this case, areas D, E, and F, with a building area of $11,150 \mathrm{~m}^{2}$, are in the eastern part of the atrium (Fig. 2), the average distance from the basement level one to the ground is $7 \mathrm{~m}$, the average width of the evacuation route is $4 \mathrm{~m}$, and the current total width of the exit is $29 \mathrm{~m}$. There are six exits in total, of which Exit 1 and Exit 6 are horizontal, Exits 2-5 are vertical with stairs or escalators and Exits 2 and 3 converge at the same ground exit.

\subsection{Plan of escape routes}

We used the iterative programming method to design the escape routes in the different areas. In this case, the iterative planning of the evacuation route was conducted in areas D, E and F (Table 1 and Fig. 3). The study assumed that there was a potential fire point in each area at different periods, so multiple escape routes were constructed in each area. Therefore, the escape routes were divided into horizontal and vertical ones, according to escape speed. Then, the study calculated the escape time required in every escape route, respectively, and discussed the effect of the location of the exits in the underground street on escape time.

\subsection{Calculation of route capability}

People may be stranded in the narrow escape paths or stairs in the underground street. Therefore, the most important thing for the design of escape routes is to consider whether

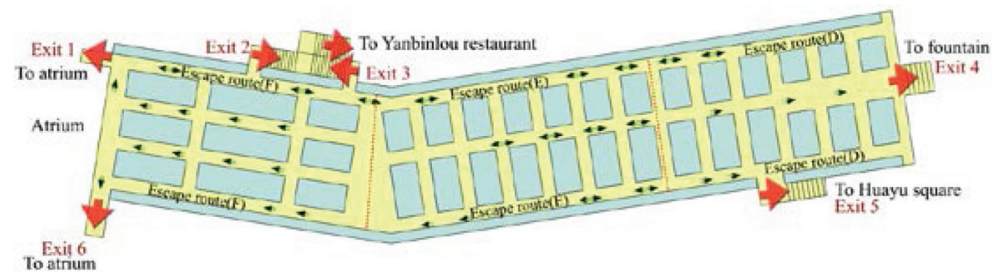

Figure 2: The Basement-1 plan of D, E and F areas in the underground street of Three Gorges Plaza.

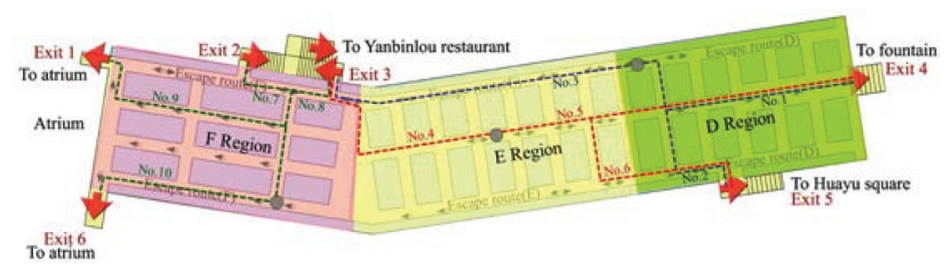

Figure 3: Plan of the iterative programming routes. 
Table 1: Plan of the iterative programming routes in the underground street of Three Gorges Plaza.

\begin{tabular}{|c|c|c|}
\hline Area & $\begin{array}{l}\text { Escape } \\
\text { routes }\end{array}$ & Plan of the iterative programming routes \\
\hline \multirow[t]{3}{*}{$\overline{\mathrm{D}}$} & No. 1 & $\begin{array}{l}\text { A location in Area } \mathrm{D} \rightarrow \text { horizontal escape routes } \rightarrow \text { vertical escape } \\
\text { routes (Exit } 4 \text { ) }\end{array}$ \\
\hline & No. 2 & $\begin{array}{l}\text { A location in Area D } \rightarrow \text { horizontal escape routes } \rightarrow \text { vertical escape } \\
\text { routes (Exit 5) }\end{array}$ \\
\hline & No. 3 & $\begin{array}{l}\text { A location in Area } \mathrm{D} \rightarrow \text { horizontal escape routes } \rightarrow \text { vertical escape } \\
\text { routes (Exit 3) }\end{array}$ \\
\hline \multirow[t]{3}{*}{$\mathrm{E}$} & No. 4 & $\begin{array}{l}\text { A location in Area } \mathrm{E} \rightarrow \text { horizontal escape routes } \rightarrow \text { vertical escape } \\
\text { routes (Exit } 3 \text { ) }\end{array}$ \\
\hline & No. 5 & $\begin{array}{l}\text { A location in Area } E \rightarrow \text { horizontal escape routes } \rightarrow \text { vertical escape } \\
\text { routes (Exit } 4 \text { ) }\end{array}$ \\
\hline & No. 6 & $\begin{array}{l}\text { A location in Area } E \rightarrow \text { horizontal escape routes } \rightarrow \text { vertical escape } \\
\text { routes (Exit 5) }\end{array}$ \\
\hline \multirow[t]{4}{*}{$\mathrm{F}$} & No. 7 & $\begin{array}{l}\text { A location in Area } \mathrm{F} \rightarrow \text { horizontal escape routes } \rightarrow \text { vertical escape } \\
\text { routes (Exit 2) }\end{array}$ \\
\hline & No. 8 & $\begin{array}{l}\text { A location in Area } \mathrm{F} \rightarrow \text { horizontal escape routes } \rightarrow \text { vertical escape } \\
\text { routes (Exit } 3 \text { ) }\end{array}$ \\
\hline & No. 9 & A location in Area $\mathrm{F} \rightarrow$ horizontal escape routes $\rightarrow$ (Exit 1 to atrium $)$ \\
\hline & No. 10 & A location in Area $\mathrm{F} \rightarrow$ horizontal escape routes $\rightarrow$ (Exit 6 to atrium $)$ \\
\hline
\end{tabular}

the number of exits and the capacity of evacuation routes can ensure the successful escape

Table 2: Parameters of the escape routes in the underground street.

\begin{tabular}{|c|c|c|c|c|c|c|}
\hline Area & $\begin{array}{l}\text { Escape } \\
\text { routes }\end{array}$ & $\begin{array}{l}\text { Length of } \\
\text { horizontal } \\
\text { escape routes }(\mathrm{m})\end{array}$ & $\begin{array}{l}\text { Narrowest } \\
\text { channel } \\
\text { width }(\mathrm{m})\end{array}$ & $\begin{array}{l}\text { Vertical } \\
\text { height of the } \\
\text { stairs }(\mathrm{m})\end{array}$ & Exit & $\begin{array}{l}\text { Exit } \\
\text { width }(\mathrm{m})\end{array}$ \\
\hline \multirow[t]{3}{*}{$\mathrm{D}$} & No.1 & 85.6 & 4.9 & 7 & Exit 4 & 4 \\
\hline & No. 2 & 73.8 & 4 & 7 & Exit 5 & 5 \\
\hline & No. 3 & 107.5 & 4 & 7 & Exit 3 & 6 \\
\hline \multirow[t]{3}{*}{$\mathrm{E}$} & No. 4 & 54.4 & 4 & 7 & Exit 3 & 6 \\
\hline & No. 5 & 119 & 4.9 & 7 & Exit 4 & 4 \\
\hline & No. 6 & 107.8 & 4 & 7 & Exit 5 & 5 \\
\hline \multirow[t]{4}{*}{$\mathrm{F}$} & No. 7 & 61.4 & 4 & 7 & Exit 2 & 6 \\
\hline & No. 8 & 58 & 4 & 7 & Exit 3 & 6 \\
\hline & No. 9 & 103 & 4 & 0 & $\begin{array}{l}\text { Exit } 1 \text { to } \\
\text { atrium }\end{array}$ & 4 \\
\hline & No. 10 & 71 & 4 & 0 & $\begin{array}{l}\text { Exit } 6 \text { to } \\
\text { atrium }\end{array}$ & 4 \\
\hline
\end{tabular}


from the underground street. First, the parameters of routes are shown in Table 2. Then, the escape time is calculated according to relevant regulations on routes, exits, including the capacity of horizontal routes, lobby, escalators, stairs, etc., and the walking speed in NFPA130. The capacity of exits in D, E and F areas of Three Gorges Plaza is shown in Table 3.

\section{SIMULATION OF ESCAPE TIME}

\subsection{Estimation of the total number of people in the underground street}

The 'method of trip generation rate' is used to estimate the capacity, and the total number of people in the underground street equals all usable areas $\times$ the crowd density in this area. According to the fact that the number of people 'following the majority of people to escape' is evenly distributed in each feature [4], the total number of people was calculated as shown in Table 4.

Among the six exits in the D, E and F area of the underground street in Shapingba, Exits 1 and 6 are the most frequently used and thus the most familiar ones. Exits 2-5 are the evacuation stairs in the middle of the underground street. Assuming that the total of people who choose the nearest stair to escape are evenly distributed across each exit, the total number of people in each exit is worked out as shown in Table 5.

\subsection{Calculation of escape time for each route and exit}

To calculate the escape time more scientifically, two calculation methods were adopted in this article to assess the safety in the underground street in Three Gorges Plaza, as shown in Tests 1 and 2.

Test $1: 22,300 /(335+335+280+280+350)=14 \mathrm{~min}>6 \mathrm{~min}$.

Test 2: According to the statistics in Table 5, the capacity for evacuees in each exit is evenly distributed across the escape routes of that exit. In the calculation of escape time, the vertical escape speed is $1.2 \mathrm{~m} / \mathrm{s}$ and the horizontal escape speed is $1.5 \mathrm{~m} / \mathrm{s}$, based on the empirical value, and the vertical escape distance is defined by the height difference. The result is shown in Table 6.

Table 3: Exit capacity in the underground street.

\begin{tabular}{|c|c|c|c|c|c|}
\hline Exit & $\begin{array}{l}\text { The location } \\
\text { of exit }\end{array}$ & $\begin{array}{l}\text { Effective } \\
\text { width (m) }\end{array}$ & $\begin{array}{l}\text { Number of } \\
\text { units }\end{array}$ & $\begin{array}{l}\text { Unit capacity } \\
\text { (ppm) }\end{array}$ & $\begin{array}{l}\text { Total unit } \\
\text { capacity (ppm) }\end{array}$ \\
\hline$\overline{\text { Exit } 1}$ & $\begin{array}{l}\text { Horizontal } \\
\text { exit }\end{array}$ & 4 & 6.7 & 50 & 335 \\
\hline Exits $2 \& 3$ & Stair & 6 & 10 & 35 & 350 \\
\hline Exit 4 & $\begin{array}{l}\text { Stair and es- } \\
\text { cape ladder }\end{array}$ & 5 & 8 & 35 & 280 \\
\hline Exit 5 & Stair & 5 & 8 & 35 & 280 \\
\hline Exit 6 & $\begin{array}{l}\text { Horizontal } \\
\text { exit }\end{array}$ & 4 & 6.7 & 50 & 335 \\
\hline
\end{tabular}


Table 4: Total number of evacuees for each feature in the underground street.

\begin{tabular}{lllll}
\hline & $\begin{array}{l}\text { Choose the } \\
\text { familiar route } \\
\text { to escape }\end{array}$ & $\begin{array}{l}\text { Choose the } \\
\text { nearest stair to } \\
\text { escape }\end{array}$ & $\begin{array}{l}\text { Find the } \\
\text { evacuation sign to } \\
\text { escape }\end{array}$ & Total \\
\hline $\begin{array}{l}\text { Weight value } \\
\text { Capacity estimation } \\
\text { (person) }\end{array}$ & 0.449 & 0.313 & 0.238 & 1 \\
\hline
\end{tabular}

Note: Weight value refers to Chen [5].

Table 5: Evacuation capacity for each exit (number of persons).

\begin{tabular}{llllll}
\hline Exit 1 & Exits 2 and 3 & Exit 4 & Exit 5 & Exit 6 & Total \\
\hline 4733 & 4733 & 4050 & 4051 & 4733 & 22,300 \\
\hline
\end{tabular}

The result of Test 1 shows that the safety of the underground street does not meet the requirement as per US NFPA.130 because the escape time exceeds $6 \mathrm{~min}$. The result of Test 2 shows that among the 10 escape routes in the $\mathrm{D}, \mathrm{E}$ and $\mathrm{F}$ areas in the underground street of Shapingba, the escape time for six of the routes is less than $3 \mathrm{~min}$, which meets the requirement in China; the escape time for four of the routes exceeds $3 \mathrm{~min}$; of these three routes exceed $5 \mathrm{~min}$, which does not meet the requirement in China. The result shows that the escape time for Exits 1 and 6, parallel with the street, is the shortest, which demonstrates that the horizontal escape to the Atrium Plaza is the most favorable for a successful escape; the average escape time of the horizontal routes accounts for $20 \%$ of the total escape time, whereas the average escape time of the vertical routes accounts for $80 \%$ of the total, which shows that the vertical escape by the stairs is the bottleneck of the total escape process.

Through the comparison between Tests 1 and 2, it is clear that the calculation criteria of US NFPA.130 are much more strict, necessitating a more strict process to meet the US disaster evacuation requirements. The result of Test 2 was much closer to the Chinese criteria, but the escape route in the underground street did not completely meet the within-3-min escape requirement, which necessitates further improvement for the underground street in Three Gorges Plaza.

\section{ANALYSIS AND DISCUSSION}

The four routes through which people cannot successfully escape the disaster are located in areas D and E. It can be seen clearly from the plan that the density of exits in areas D and E is less than that in area F, and, restricted by the terrain, areas D and $\mathrm{E}$ are asymmetric in the layout, with a poor guide to the exit. Thus, for the underground street in a mountainous city adapted from the civil air defense projects and restricted by the terrain, if the number of exits cannot be increased, top priority should be given to keeping the exits open and clear, and, at the same time, the escape time can be shortened by increasing the number squares and creating safe locations for horizontal escape. Secondly, work should be done to ensure the effective width of the evacuation route at a maximum level so as to increase the number of people per unit time and ensure the successful and effective escape of more people in the case of a disaster. 
Table 6: Length of escape routes and escape time.

\begin{tabular}{llllll}
\hline Area & $\begin{array}{l}\text { Escape } \\
\text { routes }\end{array}$ & $\begin{array}{l}\text { Time of horizontal } \\
\text { escape (s) }\end{array}$ & $\begin{array}{l}\text { Time of vertical } \\
\text { escape (s) }\end{array}$ & $\begin{array}{l}\text { Total escape } \\
\text { time (s) }\end{array}$ & $\begin{array}{l}\text { Number of } \\
\text { persons }\end{array}$ \\
\hline D & No. 1 & 57 & 224 & 281 & 2025 \\
& No. 2 & 49 & 182 & 231 & 2025 \\
& No. 3 & 71.7 & 96 & 168 & 1183 \\
E & No. 4 & 36 & 96 & 132 & 1183 \\
& No. 5 & 79 & 224 & 303 & 2025 \\
& No. 6 & 71.8 & 182 & 254 & 2026 \\
F & No. 7 & 40 & 96 & 136 & 1183 \\
& No. 8 & 38.6 & 96 & 135 & 1184 \\
& No. 9 & 70 & 0 & 70 & 4733 \\
& No. 10 & 47 & 0 & 47 & 4733 \\
\hline
\end{tabular}

\subsection{Keep the exits open and clear}

The number of entrances and exits should guarantee that all the people in the underground street can escape successfully as soon as possible. Therefore, we must pay attention to the balance of the exits in the design of the underground street, so as to prevent the excessive congestion of the crowd in some exits.

\subsection{Increase the number of anti-disaster squares}

Serving to partially enlarge the street space, the plazas in the underground street divide the streets and interpenetrate each other, which not only enlarges the street space but provides a buffer space for evacuation, thereby enhancing safety in the underground street. Moreover, due to their spaciousness, they make up for the harmful effect of the underground street on people's physiological and psychological feelings.

\subsection{Ensure effective width of the evacuation route}

Evacuation in the stairs of the underground street is the most time-consuming part of the whole process, and to ensure the effective width of vertical routes is of vital importance for the whole process of escape. However, most underground streets are adapted from civil air defense projects, and the effective width of a small number of horizontal routes is narrowed due to construction obstacles. Therefore, in the design of the underground street, the effective width of the horizontal and vertical routes should be prevented from being narrowed as much as possible to ensure the maximum capacity of people in the street.

\subsection{Formulate appropriate standards}

Comparative analysis of Tests 1 and 2 shows that different calculation methods may bring about different results. Then, the selection of anti-disaster standards appropriate for the mountainous city is particularly important. The standard in Test 2 can be adopted in the underground 
street of the old city, whereas the US standard in Test 1 can be adopted in the newly built underground street of a new city to ensure the security of the future city and to avoid as far as possible the security problems caused by design defects.

\section{CONCLUSION}

In conclusion, there currently exist problems and opportunities in disaster prevention and evacuation in the city's underground street, as shown in the simulated calculation of escape time. The study shows that the number and location of exits in the underground street is the key to successful escape, while the main bottleneck lies in the number of exits, time required for vertical escape and the effective width of the total escape routes. Furthermore, different standards may bring about different results, thus the standards selected in the design of the underground street are of vital importance. Based on this, the implementation of a comprehensive disaster prevention system can be promoted. Under the guidance of comprehensive disaster prevention planning, the combination of the planning and implementation of evacuation routes and the underground civil air defense projects in the city can ensure the safety of people's lives and property as well as a secure city seldom struck by disasters.

\section{ACKNOWLEDGEMENT}

This research was supported by the National Natural Science Foundation of China (No. 51378516).

\section{REFERENCES}

[1] Zhou, T.J., Yan, Q. \& Zuo, J., Analysis of sight and activity of safe escaping in underground commercial space - taking Chongqing underground commercial space as example. Disaster Advances, 3(4), pp. 157-162, 2010.

[2] Marciano, F.A. \& Vitetta, A., Risk analysis in road safety: an individual risk model for drivers and pedestrians to support decision planning processes, International Journal of Safety and Security Engineering, 1(3), pp. 265-282, 2011. doi: http://dx.doi. org/10.2495/safe-v1-n3-265-282

[3] Russo, F. \& Chila, G., Integrated travel demand models for evacuations: a bridge between social science and engineering, Safety and Security Engineering, 4(1), pp. 19-37, 2014. doi: http://dx.doi.org/10.2495/safe-v4-n1-19-37

[4] Zhang, H.W., A Study on Optimum Urban Disaster Evacuation Route by a MADM Approach, Feng Chia University: Taiwan (online), available at http://web.lib.fcu.edu.tw/ library/

[5] Chen, D.L., A Study of Guides on Human Evacuation Behaviors in MRT Underground Stations, National Taipei University of Technology: Taiwan (online), available at http:// library.ntut.edu.tw/files/11-1007-2464.php

[6] Liang, W.L., A VR Simulation Study of Choosing Exit in Underground Arcades, National Taipei University of Technology: Taiwan (online), available at http://pc01.lib. ntust.edu.tw/ETD-db/ETD-search-c/view_etd?URN=etd-0204110-132729

[7] Chen, Z.L., Preliminary discussion of the disaster prevention square in urban underground public space. Chinese Journal of Underground Space and Engineering, 2(2), pp. 280-283, 2006. 
[8] Zeng, S., Ma, X.Q. \& Liao, Y.F., Analysis of flees for life model during a fire in underground business street. Chinese Journal of Underground Space and Engineering, 4(2), pp. 374-379, 2008.

[9] Huang, L.L., Theoretical calculation and software simulation on the evacuation time of the occupants in the underground commercial building. Journal of Safety Science and Technology, 8(2), pp. 69-73, 2012.

[10] National Standard Information Sharing Infrastructure, Fire protection design of civil air defense works, GB 50098-2009, Beijing, available at http://www.cssn.net.cn/pagesnew/ search/standard_detail.jsp?hasElec $=1 \& \mathrm{a} 001=\mathrm{NjA} 4 \mathrm{NjczOA}==$

[11] Wang, Y.G. \& Zhang, C.B., Alternative route strategy for emergency traffic management based on ITS: a case study of Xi' an Ming City Wall. Tehnički vjesnik-Technical Gazette, 20(2), pp. 359-364, 2014.

[12] Hong, R.R., Design of the safe evacuation in Metro, Urban Rapid Rail Transit, 20(2), pp. 18-21, 2007.

[13] Zhang, X.T., Wang, S.L., Wang, J.J. \& Giacomo, R., A simplified model to predict smoke movement in vertical shafts during a high-rise structural fire. Journal of Engineering Science and Technology Review, 7(2), pp. 29-38, 2014.

[14] Zhou, X.S., Shortest path problem and its solution methods study. Computer Knowledge and Technology, 6(6), pp. 1403-1405, 2010. 